\title{
Michel Marie e a poesia do olhar
}

Professor da Universidade Sorbonne (III) e autor de livros já incorporados à cultura cinematográfica no âmbito acadêmico, como "Dicionário teórico e crítico de cinema" e "A estética do filme", ambos em coautoria com Jacques Aumont, Michel Marie pode ser considerado, hoje, um dos principais teóricos franceses e mundiais da história do cinema. Acaba, ainda, de lançar, junto com Laurent Jullier, "Lires les images de cinéma", pela Larousse, no qual apresenta as ferramentas da análise fílmica, considerando as escalas do plano, da seqüência e do filme, e reflexões sobre o Cinema Mudo, a Idade de Ouro dos gêneros, as lições de vida do classicismo, o cinema da modernidade, o segundo sopro de Hollywood e a era pós-moderna. Para ele, analisar um filme é, acima de tudo, uma questão de prazer, o que demonstrou, claramente, durante o seminário ministrado de 7 a 11 de maio de 2007, a convite do Programa de Pós-graduação em Comunicação Social, sobre "A história do cinema e seus métodos", na PUCRS. Marie focou as aulas no trabalho de quatro diretores emblemáticos da indústria cinematográfica, dois franceses, um norte-americano e um russo: Georges Méliès (1861-1938), Buster Keaton (1895-1966), Sergei Eisenstein (1898-1948) e Jean-Luc Godard (1930-).

Marie também deu uma palestra aos alunos de graduação da Famecos a respeito da Nouvelle Vague francesa, uma de suas especialidades. O livro de sua autoria, "La Nouvelle Vague - Une école artistique", publicado pela Nathan, em 1997, é um clássico para cinéfilos e acadêmicos. Portanto, Marie não poderia deixar de tocar no assunto, sobretudo porque, aqui no Brasil, a Nouvelle Vague francesa teve forte influência para uma geração de cineastas oriundos do Cinema Novo, entre os quais Nelson Pereira dos Santos. Na atualidade, o movimento ainda serve de referência para um certo estilo cinematográfico, principalmente no que diz respeito ao aspecto artesanal na produção de filmes, para ficar apenas em uma faceta técnica, sem falar na condição poética de uma visão autoral.

Na opinião de Marie, é preciso ter extrema cautela quando o assunto é história - definida como uma sucessão temporal de acontecimentos que determinam a evolução de uma sociedade com base nas permanências e nas mudanças - do cinema. Antes de o cinema ser comentado por cinéfilos, digamos, foram os jornalistas e os críticos que fizeram a sua história. Nesse contexto, o que determina a seleção estética são os juízos de valores. Por isso, a questão que se coloca sobre como fazer história da arte é das mais pertinentes, segundo ele. Marie lembra que o que chama de história científica do cinema não che- ga a ter 30 anos, desenvolvendo-se, principalmente, nos Estados Unidos, na Itália, na França, na Espanha e, em parte, no Brasil. Ele observa que, no início dos anos 1980, a história do cinema se depara com uma reorientação epistemológica. Os primeiros livros de história do cinema tratavam, apenas, de conteúdo técnico, a partir de descrições das invenções do século XIX e do retrato desses pioneiros da indústria. Nos anos 60, porém, a pesquisa já se expandira.

\section{A burguesia francesa só admitiu o cinema por causa de sua função documental, porque a ficção era menosprezada por ser uma distração popular.}

Cineastas também deram sua contribuição. D.W. Griffith (1875-1948), por exemplo, chegou a escrever sua biografia na terceira pessoa. Méliès, por sua vez, escreveu, em 1908, "A visão cinematográfica", que serviu como espécie de redescoberta por parte dos surrealistas em 1923/24 e que o transformou em um mito do cinema. Também entre os períodos do cinema mudo e falado surgem muitas histórias, o que acaba incentivando a criação de cinematecas. Os críticos dos anos 1920 acabam resgatando, nos 1930, por não conseguirem admirar filmes contemporâneos, os títulos antigos de sua preferência. Consta que a primeira cinemateca surgiu em Estocolmo, na Suécia, em 1934. O cinema escandinavo, aliás, foi o primeiro a ter uma ambição artística. De lá, um dos diretores mais conhecidos é Ingmar Bergman, admirado e adorado pelos franceses da Nouvelle Vague.

Do ponto de vista estético, a primeira história do cinema aparece em 1935, na França, de autoria de Maurice Bardèche e Robert Brasillach. Conforme Marie, ela ainda tem um cunho acentuadamente literário. Ambos tinham, ainda segundo Marie, muito preconceito em relação ao cinema norte-americano. No entanto, serviu de referência para várias gerações de cinéfilos, como Henri Langlois, que o tinha como livro de cabeceira.

Esse livro glorifica o autor, portanto, sem levar em conta os produtores. Só a partir dos anos 1970 é que se começa a considerar que é necessário rever os filmes para escrever sobre eles.

Em resumo, Marie aponta três caminhos para se fazer história do cinema: 
1. Definir o princípio de pertinência, estabelecendo um certo eixo explicativo, estilístico e metodológico

2. Definir uma metodologia rigorosa

3. Definir as fontes e materiais de referências, o que pode ser difícil, reconhece ele, em função do grande número, hoje, de material de pesquisa, em determinados casos.

\section{8 de dezembro de 1895 é a data da primeira sessão pública e paga de cinema. Havia sessões em Nova York e Berlim, com outros aparelhos, só que mais fechadas e quase confidenciais.}

No caso de Méliès, Marie destaca que "Le voyage dans la lune" ("A viagem à lua", 1902), teve um retorno excepcional, com 200 cópias de tiragem. Os filmes, naquela época, eram vendidos, e não locados. Quando Pathé passou da venda à locação, explica o professor, aumentou o volume da produção de filmes e, ao mesmo tempo, decretou a morte de Méliès, um artista-artesão que controlava todas as fases da produção mas que era um péssimo homem de negócios. Chamado de "cinema primitivo", termo contestado por alguns professores, o trabalho de Méliès, porém, tem o mérito de criar trucagens e ampliar o horizonte cinematográfico com espetáculos de magia, em que uma imagem substitui a outra pela montagem. Em "A viagem à lua", Méliès inspira-se nas narrativas de Jules Verne (1828-1905) e nas operetas do compositor Jacques Offenbach (18191880). Os selenitas - habitantes da lua - são inspirados no romance de H. G. Wells (1866-1946), “A máquina do tempo". Para Marie, o que chama a atenção no filme de Méliès é a riqueza do cenário: "Para nós parece rudimentar, mas, naquela época, tinha o mesmo efeito que os filmes de ficção científica de hoje". Em Méliès, o estilo dito primitivo se caracterizava pela câmera ao fundo da sala e não identificação entre os personagens, entre outros detalhes. A grande produção tanto de Lumière quanto de Méliès era uma prova da força que o cinema começava a adquirir desde o seu nascimento. "É um período bastante rico e complexo", afirma Marie.

Complexo também é o universo de Buster Keaton, cuja característica principal era o fato de não sorrir e, no que diz respeito a sua formação, não ter freqüentado a conhecida escola de Mark Sennet, de onde saiu Charlie Chaplin (1889-1977). No filme "A general", referência ao nome da locomotiva, por isso o artigo feminino " $a$ ", Keaton tinha 31 anos de idade. $O$ fato de ele ter tido um treinamento físico precoce, por ter aprendido acrobacias quando era criança, facilitava a encenação sem dublês. "A general" trata do resgate de uma locomotiva roubada por espiões do Norte durante a Guerra da Secessão. Os filmes de Keaton tiveram sucesso, mas ele sempre passou por problemas financeiros. Com a passagem para o cinema falado, Keaton fica praticamente desempregado. Ficou hospitalizado e morreu pobre. "O que me parece extraordinário é a maneira com que Keaton usa a linguagem cinematográfica", diz Marie.

Quem também usa a linguagem cinematográfica com maestria, opina Marie, é o russo Sergei Eisenstein em "Outubro" (1927). Nesse filme, destacam-se, de acordo com Marie, as representações do poder por meio da propaganda, o poder das armas por meio da força militar e o poder dos símbolos por meio das representações. Era importante, no filme, substituir os velhos por novos símbolos. Para Marie, Eisenstein usa quase um tratamento psicanalítico da revolução, grande leitor de Freud que era. Havia fortes contradições culturais na família do cineasta, cuja mãe era judia da Lituânia, Eisenstein era homossexual, opção sexual condenada por bolcheviques. "No entanto, a homossexualidade de Eisenstein era tolerada." Um aspecto interessante no filme, de acordo com Marie, é o fato de a revolução nunca ser definitiva, já que Eisenstein mostra, no fim, que as forças revoluncionárias têm de continuar lutando pelos seus símbolos: "o filme foge ao culto da personalidade".

A personalidade de Godard, por sua vez, está por inteira nos filmes que dirige. $\mathrm{O}$ que não é diferente com "Une femme est une femme" ("Uma mulher é uma mulher"), de 1961. Um dos cinco principais diretores da Nouvelle Vague, junto com François Truffaut (1932-1984), Jacques Rivette, Eric Rohmer e Claude Chabrol, Godard teve um reconhecimento cedo. Em "Acossado" (1959), com roteiro de Truffaut, o protagonista vivido por Jean-Paul Belmondo corre, no final, até ficar sem fôlego, o que dá o título do filme: "À bout" é no limite, e "souffle" é fôlego ("À bout de souffle" é o título em francês). O jogo de palavras é uma característica de Godard (o que Marie também aprecia nele). Uma das obras sobre o diretor é "Godard au travail" (Cahiers du Cinéma, 2006), por Alain Bergala, em que analisa a produção e a direção de todos os longas do diretor francosuíço, de "Acossado" até "Weekend à francesa" ("Weekend", 1968). Para Marie, “Uma mulher é uma mulher" é o único filme alegre e divertido de Godard, além de cômico e burlesco. Godard ficou surpreso com o fracasso comercial do filme, "o que 
pode ser explicado pelo humor suíço com o qual só ele ria".

O roteiro inicial é de uma atriz francesa em ascensão, Geneviève Cluny, que atuou em "Les cousins" ("Os primos"), de Chabrol. Roteiro: uma mulher casada queria ter um filho, mas o marido prefere esperar. Ela, então, ameaça ter a criança com o amigo do casal. Godard adapta o roteiro para a região de Strasbourg Saint Denis, um bairro popular, inspirado em "Sob os tetos de Paris" ("Sous les toits de Paris", 1930), de René Clair (1898-1981). "O gênio de Godard foi introduzir a coreografia da comédia musical e a encenação", salienta Marie.

Um aspecto curioso no filme, destaca Marie, é o fato de o cabaré ter uma certa infantilidade ao estilo das histórias de Lewis Carroll. Hoje, o nome de Godard, na França, é controvertido: "Tornou-se uma instituição, mas tem muitos inimigos".

As escolhas de Marie, que não se contenta em reproduzir a história, mas ampliá-la e até contestála, se aproximam do perfil dos quatro cineastas analisados. Todos eles mostram um aspecto obscuro da indústria, o da marginalidade, que, por isso mesmo, enriquece o fazer cinematográfico. É o outro lado. Marie, com um agudo e preciso senso de observação, sem menosprezar a sensibilidade, faz da análise fílmica uma poesia do olhar.

REVISTA FAMECOS Seria justo afirmar que o gênero ficcional teria começado com Méliès, ao passo que o gênero documental com os irmãos Lumière?

MICHEL MARIE Trata-se de uma oposição bastante clássica na história do cinema, na medida em que Lumière fez, sobretudo, vistas descritivas de caráter documental e apenas alguns pequenos filmes de ficção. Méliès, por sua vez, fez, no início, alguns filmes como os de Lumière e depois filmes fantasiosos, mas também fez o que poderíamos chamar de "atualidades reconstituídas", como "Le couronnement du roi Édouard VII e "Éruption volcanique à la Martinique", ambos de 1902. O que se passou é que nos anos 60 o diretor da Cinemateca Francesa, Henri Langlois, criou o paradoxo, que foi usado por Godard em discurso na própria Cinemateca e nos diálogos de "A chinesa" ("La chinoise", 1967). Como Godard e Langlois gostavam muito desses paradoxos, eles inverteram os valores: acentuaram o aspecto artístico e ficcional de Lumière, considerando-o "o último pintor impressionista", para colocá-lo na história das artes plásticas. Insistiram, por outro lado, na ligação de Méliès com a realidade, sobretudo com atualidades políticas, como "L'affaire Dreyfus" (1899). Portanto, Méliès teria feito alguns filmes que poderiam ser considerados, hoje, como as notícias televisivas. Esse paradoxo, porém, tem limites.

RF E quais são estes limites?
MM Há muitas idéias interessantes, de fato, que permitem aprofundar o lado artístico do cinema de Lumière, mas, ao mesmo tempo, os Lumière prefiguram o catálogo dos filmes documentais que foram produzidos nos anos seguintes e que Gaumont, Pathé e Éclair lançaram. A burguesia francesa só admitiu o cinema por causa de sua função documental, porque a ficção era menosprezada por ser uma distração popular. Afirmar que Méliès era documentarista é bastante discutível. Apenas de 15 a $20 \%$ de seus filmes falam de atualidades, enquanto o resto é pura ficção. Esses dois modelos estéticos em oposição atravessam toda a história do cinema. Pode-se ver no cinema realista herdeiros de Lumière até Jean Eustache (1938-1981), Maurice Pialat (19252003) etc., passando por Jean Renoir (1894-1979) e Jean Vigo (1905-1934), enquanto o trabalho de Méliès diz respeito à materialidade das imagens e ao cinema de animação. Assim, eu penso que a oposição tradicional parece justa do ponto de vista histórico e que o paradoxo godardiano é interessante enquanto paradoxo. Eu gostaria de acrescentar que essa oposição entre Lumière e Méliès é algo bem característico e arraigado da cultura francesa.

\section{Não sou especialista em Internet, mas o que muda com ela é o fato de tornar acessível todos os filmes para todo mundo.}

RF Esse paradoxo nos remete também à questão dos limites entre realidade e ficção no cinema.

MM Com certeza. Eu dei um curso em Campinas sobre a influência do documentário sobre a ficção, e vice-versa. Mas se trata de uma distinção institucional, econômica e da qual se fala muito em função da história.

RF É um mérito dos irmãos Lumière o fato de terem conseguido efetuar a sintese entre imagem e movimento com a invenção do cinematógrafo, já que, segundo o historiador francês Vincent Pinel, em "Louis Lumière - Inventeur et cinéaste" (Paris, Nathan, 1994), nenhum aparelho, no final de 1894, conseguia projetar em uma tela simultaneamente a fotografia e o movimento de uma cena com alguma duração?

MM É um amplo debate. Mas eu estou de acordo com Pinel, que reproduz a tese clássica dos últimos 15-20 anos. $\mathrm{O}$ que Lumière acrescentou, na verdade, foi o mecanismo intermitente de projeção, utilizado na 
indústria têxtil, que foi transposto para a câmera. Edison tinha inventado o quinetoscópio para que se visse a animação de uma maneira individual. É verdade que Émile Reynaud, Jules Marey e Thomas Edison inventaram, todos eles, alguns componentes decisivos para o cinema e que os Lumière, como industriais e bons inventores que eram, conseguiram sintetizar todas essas invenções. O cinematógrafo era simples e prático. Como eles tinham uma rede de produção e de venda de "cartões fotográfi$\cos ^{\prime \prime}$, o aparelho foi difundido rapidamente. Mas como todo mundo se interessava por isso, durante uma década, Lumière ficou com a exclusividade comercial do aparelho por cerca de doze anos. A data de 28 de dezembro de 1895 é a data da primeira sessão pública e paga de cinema. Havia sessões em Nova York e Berlim, com outros aparelhos, só que mais fechadas e quase confidenciais. O cinematógrafo foi, acima de tudo, um sucesso comercial. Havia uma grande curiosidade em relação às imagens em movimento naquela época, com projeção de fotos, o que significa dizer que o cinema não chegou até onde havia chegado sozinho.

\section{Eu, por exemplo, nunca vejo televisão, porque considero a televisão comercial catastrófica. Ao mesmo tempo, trata-se de um meio espetacular de produção e difusão.}

RF Então, é justo considerar que os irmãos Lumière inventaram o cinema?

MM É sempre reducionista afirmar desse modo. Eles criaram, em 1895, em plena época do imperialismo europeu e de um nacionalismo exacerbada, uma invenção "francesa", nesse contexto. Para os livros publicados nos Estados Unidos, quem inventou o cinema foi Thomas Edison. Não é de todo absurdo. A questão toda gira em torno da palavra "cinema". Edison inventou o quinetoscópio e os Lumière inventaram o cinematógrafo. $\mathrm{O}$ nome que ficou foi "cinema", como a marca Frigidaire para refrigerador. Nos Estados Unidos, cinema se caracterizou por indicar filmes de arte, mas não os "blockbusters". Lá, fala-se "movies", e não cinema.

RF É verdade que Louis Lumière teria dito: "Le cinéma n'a aucun avenir" ("O cinema não tem futuro algum?")? ${ }^{1}$

MM É uma citação que Godard colocou em “O desprezo" ("Le mépris", 1963), mas é inventada. Origi- na-se de uma frase que Lumière teria dito a Méliès e que Méliès conta dez ou quinze anos depois. Ele, Méliès, queria adquirir um cinematógrafo para espetáculos no teatro Robert Houdin, mas Lumière queria ter a exclusividade no uso do equipamento. Portanto, ele disse que o cinematógrafo não teria futuro comercial justamente porque não queria vendê-lo. Isso quer dizer, também, que Lumière acreditava no futuro da película mas não havia, de forma alguma, previsto que se poderia utilizar o cinematógrafo como forma de espetáculos em salas específicas para esse fim. Méliès, logo depois, compreendeu bem essa questão.

RF Por falar em indústria, muito valorizada nos Estados Unidos, principalmente, gostaríamos de saber qual é a relação entre a distribuição e a influência cultural dos filmes? Houve época, no Brasil, em que alguns filmes não chegavam de um estado a outro. Isso começou a mudar com a difusão de novos meios eletrônicos, como o videocassete e a Internet?

MM A distribuição, e não a produção, é que foi globalizada. Mesmo os Estados Unidos produzem alguns filmes que procuram o mercado interno, e que não são feitos, de início, como produto de exportação. O que é mundial é a difusão dos filmes de grande orçamento, o que sempre existiu. Se analisarmos o que se passou entre 1918 e 1923 havia filmes de grande orçamento que eram difundidos em todo o mundo, sobretudo os norte-americanos. Não sou especialista em Internet, mas o que muda com ela é o fato de tornar acessível todos os filmes para todo mundo. Digamos que, ao mesmo tempo, os internautas não irão se deparar ao acaso com determinado filme, o que até pode acontecer. Permite que os filmes raros, jamais vistos antes, possam encontrar algum tipo de público.

RF Como fica a questão legal da difusão de filmes pela Internet, considerando que a França, nesse aspecto, procura resguardar o mercado para os filmes nacionais por meio de leis específicas para o audiovisual?

MM Nós tivemos uma série de debates na Assembléia Nacional sobre essas questões de direitos do autor, do distribuidor etc. É bastante difícil gerenciar esse problema. Na verdade, são os produtores que acabam beneficiados, e não os autores.

RF No Brasil, há uma eterna luta entre a televisão e o cinema. Acusa-se o cinema de ter, por causa do apoio de empresas televisas na produção de filmes, uma estética demasiado televisiva. Acontece algo semelhante na França?

MM Acontece em todo o mundo, não só no Brasil. Todos os países que têm um cinema forte lutam contra a televisão. E há países que não têm cinema, e, portanto, a televisão está sozinha. Certamente a 
"estética televisiva" é um problema, porque significa a "estandartização" da linguagem cinematográfica, caracterizada por uma certa forma de montagem, de relação entre a imagem e a música. É contraproducente, pois, na televisão, há pequenos denominadores comuns, a fim de ter o máximo de espectadores. A televisão precisa encontrar uma linguagem que esteja na moda e que esteja de acordo com o "standard" da época. Na França, em parte, acontece o mesmo. Mas como o cinema francês é vasto em termos artísticos e de quantidade, há muitos filmes que escapam desse modelo televisivo, mas, ainda assim, influencia muito os jovens cineastas. Eles vivem uma contradição: para que o filme seja visto é preciso que seja comprado pela televisão. Nas salas de cinema, há filmes que fazem sucesso, claro, mas não muitos. Eu, por exemplo, nunca vejo televisão, porque considero a televisão comercial catastrófica. Ao mesmo tempo, trata-se de um meio espetacular de produção e difusão. Os telefilmes se parecem, mas, por outro lado, alguns seriados policiais norte-americanos são bastante criativos do ponto de vista do roteiro, da montagem e do ritmo. Se pegarmos o cinema clássico ou mudo, os filmes de Louis Feuillade (1874-1925), os westerns dos anos 50 também eram concebidos sob um modelo comercial. Tenho certeza que nos seriados televisivos contemporâneos encontramos formas artísticas inovadoras.

RFAs cinematecas preservam filmografias em categorias fílmicas que não estão na historiografia oficial, como os cinejornais e filmes domésticos. Como o senhor encara a inclusão dessas categorias ditas "menores" na historiografia que já está se fazendo hoje? O senhor as considera, principalmente em relação aos filmes domésticos, produção cinematográfica?

\section{Há regiões no interior da França onde algumas crianças nunca viram um filme, $e$, portanto, professores podem levá-las até uma sala de cinema, 0 que pode estimular a freqüência ao cinema.}

MM Trata-se de um fenômeno mundial. A Cinemateca Francesa, por exemplo, conservou filmes de ficção. A Biblioteca Nacional da França, na rua Tolbiac, integrou um Departamento de Audiovisual com grandes produções, e privilegiou os documentários. Em todo caso, na França, nos Estados Unidos e na Inglaterra, eu creio, está havendo uma importante tomada de consciência da parte de antropólogos, sociólogos e historiadores em considerar o cinema como fonte de pesquisa, e isso não existia há 20 anos. É possível, na minha opinião, colocar filmes domésticos ao lado de produções como a de Méliès, mas é preciso também considerar seus limites.

RF Até que ponto o ensino do cinema nas universidades gera ou influencia resultados práticos na produção de filmes na França?

MM Na França, é muito pouco. Existem dois ou três departamentos que assinam a co-produção de alguns documentários, como em Toulouse, Nancy e Paris VIII, mas não é o caso das outras universidades, que privilegiam a história, a estética do filme. $\mathrm{O}$ ensino universitário forma espectadores mais cultivados no cinema. Até pode formar cineastas. Estes, no entanto, são formados, principalmente, por escolas profissionais da França. Alguns estudantes podem até se tornar cineastas ou trabalhar na equipe de produção de filmes, mas é uma exceção. Cédric Klapisch, por exemplo, entre outros, passaram por esse ensino universitário e acadêmico. Da parte dos professores universitários franceses, não existe essa mentalidade de formar cineastas. Agora, da parte dos alunos, é uma outra questão. Todos eles querem filmar.

RF $O$ programa de ensino do cinema nas escolas é uma particularidade da França?

MM Eu penso que sim. Na Inglaterra, há filmes adquiridos pelo British Institute que podem ser exibidos nas salas de aula ou estudados nas escolas, mas não sei se é para os mais jovens ou velhos estudantes. Há um esforço, na Inglaterra, em integrar o cinema ao ensino. Na França, essa integração ainda é marginal: são 100 escolas no total de cerca de 15 mil. Mas, por outro lado, há uma outra prática que permite ao professor acompanhar os estudantes às salas de cinema. Por exemplo, há regiões no interior da França onde algumas crianças nunca viram um filme, e, portanto, professores podem levá-las até uma sala de cinema, o que pode estimular a freqüência ao cinema.

RF Pode-se falar, ainda hoje, tanto na França como em outros países, uma "escola" cinematográfica, no sentido artístico da expressão?

MM É difícil dizer. Isso serve para os historiadores no sentido de identificar correntes, o que só se pode fazer "a posteriori": se há, por exemplo, uma estética do filme asiático que parece ter pontos em comum com os filmes realistas ingleses. Mas, para ser uma escola, tem de contemplar cineastas que têm pontos em comum, e não só com um deles. 
RF Quando começa e acaba a Nouvelle Vague, um dos movimentos mais importantes da história do cinema francês e mundial?

MM Pode-se pegar o curta-metragem de Jacques Rivette, "Le coup de Berger", de 1956, ou os dois primeiros "longas" de Claude Chabrol, lançados em fevereiro e março de 1959. O início depende se especificarmos a Nouvelle Vague a partir dos curtas ou dos longas-metragens. Eu penso que é preferível pegarmos os longas porque, no meu entender, a Nouvelle Vague existe a partir do momento em que é vista pelo público. Ou seja, a partir de "Le beau Serge" ("Nas garras do vício") e "Les cousins", que tiveram bastante sucesso. Antes, até existia, mas era confidencial e experimental. Os historiadores divergem em relação ao fim dela. Para mim, ela termina nos anos 1964/65. O auge foi de 1959 a 1962, e, depois, começa a diminuir sua força. Acho, no entanto, absurdo afirmar que alguns filmes contemporâneos sejam da Nouvelle Vague.

RF Comenta-se que a Nouvelle Vague teria provocado a falência dos estúdios e de salas de cinema? É verdade?

MM Não, de forma nenhuma. A Nouvelle Vague acompanhou a mutação do mercado. Ou seja, o cinema era um lazer para toda a sociedade, a partir do cinema falado e até os anos 60, mas, na época em que a televisão começou a se difundir, estava em tudo que era lugar, houve uma divisão de público. Havia filmes de família e filmes mais intelectualizados, como na literatura havia romances ambiciosos e outros mais populares. Havia filmes, porém, que se situavam entre essas duas tendências, como "O último metrô" ("Le dernier métro", 1980"), de Truffaut, um filme tanto pessoal quanto de grande sucesso de público. Também fez filmes atípicos como "O quarto verde" ("La chambre verte", 1978) ou "O garoto selvagem" ("L’enfant sauvage", 1970), e outros mais fáceis em comparação com os de Godard.

RF Quais são os critérios para considerar um filme representativo e legítimo da Nouvelle Vague?

MM Eu propus esses critérios em meu livro ("La Nouvelle Vague" - Une école artistique", Paris, Nathan, 1997). Há bons e maus filmes. A Nouvelle Vague também produziu filmes ruins, superficiais. Os critérios, no meu ponto de vista, são mais técnicos: som direto, improvisação, cenário natural e o fato que o realizador era, ele mesmo, o roteirista.

\section{NOTAS}

* Entrevista concedida a Eduardo Portanova Barros, doutorando do PPGCOM e bolsista CNPq-Brasil. Essa entrevista também contou com a participação de Carlos Gerbase e Helena Stigger.

1. Em entrevista concedida ao historiador francês Georges Sadoul, publicada no livro de sua autoria, "Louis Lumière", da coleção Cinéma d'Aujourd'hui ( $\left.\mathrm{n}^{\circ} 29\right)$, da editora Seghers, em 1964, Louis Lumière afirmou que não assistira à sessão no Grand Café, pois estava em Lyon. Segundo ele, se a frase de que "o cinema não tem futuro" foi pronunciada, ela teria sido dita, nesse dia 28 de dezembro de 1895, por seu pai, Antoine. Louis acrescentou que o que era verdade no que dizia respeito a ele é que não acreditava que o cinematógrafo pudesse prender a atenção do público por várias horas seguidas. Ainda conforme a entrevista, de acordo com Louis Lumière e de uma carta que ele escreveu em 1945 em Becy, seu pai teria dito a Méliès: "Jeune homme. Mon invention n'est pas à vendre, pour vous ce serait la ruine. Elle peut être exploitée quelque temps comme une curiosité scientifique. En dehors de cela, elle n'a aucun avenir commercial". Tradução livre: "Meu jovem. Minha invenção não está à venda. Para você, seria a ruína. Ela pode ser explorada por algum tempo como uma curiosidade científica. Fora disso, ela não tem qualquer futuro comercial". Para Sadoul, portanto, é Antoine, o pai, que teria feito algum comentário nesse sentido, e não Louis, que não estava em Paris em 28 de dezembro de 1985, como comprova a correspondência da época. 